\title{
Extended-gate-type Organic Field-effect Transistors for the Detection of Potential Psychological Stress Markers
}

\author{
Pierre Didier, ${ }^{1,2}$ Hans Blomenkamp, ${ }^{1,3}$ Riku Kubota, ${ }^{1}$ \\ Yui Sasaki, ${ }^{1}$ and Tsuyoshi Minami ${ }^{1,2^{*}}$ \\ ${ }^{1}$ Institute of Industrial Science, The University of Tokyo, 4-6-1 Komaba, Meguro-ku, Tokyo 153-8505, Japan \\ ${ }^{2}$ LIMMS/CNRS-IIS (UMI2820), The University of Tokyo, 4-6-1 Komaba, Meguro-ku, Tokyo 153-8505, Japan \\ ${ }^{3}$ Institute of Electronic and Sensor Materials, Faculty of Materials Science and Materials Technology, \\ Technische Universität Bergakademie Freiberg, Gustav-Zeuner-Straße 3, Freiberg 09599, Germany
}

(Received August 31, 2020; accepted October 13, 2020)

Keywords: organic field-effect transistor, biosensor, extended-gate-type electrode, psychological stress biomarkers

Organic field-effect transistors (OFETs) are promising electronic devices owing to their attractive features such as a low cost, solution processability, and ease of use. In this regard, we have fabricated extended-gate-type OFETs functionalized with natural molecular recognition materials as biosensors for the detection of biomarkers. Toward the development of a potential psychological stress monitoring method based on OFETs, we have successfully detected three types of psychological stress biomarkers: chromogranin A ( $\mathrm{CgA})$, immunoglobulin A ( $\operatorname{IgA})$, and nitrate $\left(\mathrm{NO}_{3}\right)$. The OFETs reproducibly respond to the biomarkers, demonstrating their ability to detect potential psychological stress in individuals. Notably, the detectability of the OFETs makes them suitable for the analyses of real samples. Thus, we strongly believe that the developed system based on extended-gate-type OFETs could be employed as a sensor platform for biosensor applications in the field of healthcare.

\section{Introduction}

Psychological stress is caused by various stressors that disturb internal processes for the functioning of living organisms. The peripheral and central nervous systems react to this psychological stress through complex mechanisms such as physiological or behavioral adaptation to restore homeostasis and to prevent excessive responses. ${ }^{(1)}$ Short-term psychological stress boosts the immune system, while chronic psychological stress causes the overdrive of multiple systems. ${ }^{(2)}$ The latter stress can lead to suppression of the immune system, ${ }^{(3)}$ atherosclerosis (plaque buildup in arteries), increased risk of diabetes mellitus, ${ }^{(3)}$ or abnormal secretion of gastric acid, which can cause peptic ulcers. ${ }^{(3,4)}$ Psychological stress can also lead to epigenetic changes such as methylation of cytosine nucleobases ${ }^{(5)}$ or amino acid residues of histones (i.e., lysine and arginine). ${ }^{(6)}$ Although the DNA sequence remains unchanged, the methylated nucleobases and histones lead to gene silencing. As a consequence, abnormal protein production can affect *Corresponding author: e-mail: tminami@iis.u-tokyo.ac.jp https://doi.org/10.18494/SAM.2021.3066 
behavioral and physiological traits. Another serious problem of psychological stress is that it affects the economy. In the U.K., 13.4 million working days were lost by $1.3 \%$ of the workforce who were negatively influenced as a consequence of psychological stress such as depression and anxiety. ${ }^{(7)}$

Saliva, which is also called "the mirror of the body", ${ }^{(8,9)}$ is already used in many studies for measuring psychological stress biomarkers because it can be collected easily and noninvasively. ${ }^{(10,11)}$ In comparison with blood and urine, saliva has many advantages as a real sample, ${ }^{(12)}$ because it can be used as responses to acute ${ }^{(13)}$ and long-term mental stresses. ${ }^{(14)}$ This body fluid is derived from the ultrafiltration of blood ${ }^{(15)}$ and is secreted by the glandula sublinguallis, the glandula submandibularis, and the parotid gland. Even though many markers are also present in blood, saliva is preferred for noninvasive diagnoses because it shows the highest variability in concentration due to acute psychological stress. Many different biomarkers related to psychological stress such as $\alpha$-amylase, ${ }^{(16)}$ cortisol, ${ }^{(10)}$ and cortisone hormones $^{(17)}$ can be investigated using saliva. In addition, saliva has the advantage for laboratory technicians and clinical staff because they are not exposed to pathogens.

To realize simple methods for psychological stress detection, we believe that organic fieldeffect transistors (OFETs) are among the most promising electronic devices. OFETs have several attractive features including light weight, flexibility, durability, solution processability, and compact integration. ${ }^{(18-23)}$ Furthermore, OFET-based devices can directly read out molecular recognition phenomena of receptors as electrical signals, suggesting that the devices can be employed for psychological stress detection. To date, several psychological stress biomarkers have been successfully detected using OFET-based sensors. ${ }^{(24-27)}$ In this Perspective, we summarize our recent progress in detecting psychological stress biomarkers based on extended-gate-type OFETs. The detectability of three types of psychological stress biomarkers [i.e., chromogranin A $(\mathrm{CgA}),{ }^{(28)}$ immunoglobulin $\mathrm{A}(\operatorname{IgA}),{ }^{(29)}$ and nitrate $\left(\mathrm{NO}_{3}\right)^{(30)}$ ] using OFETs is reported.

\section{Extended-gate-type OFETs as Sensing Platform for Biomarkers}

An OFET consists of two distinct parts, the drive part (i.e., the OFET device) and the detection part (i.e., the functionalized extended gate) as shown in Fig. $1 .^{(31,32)}$ The extended gate can be functionalized by immunoproteins or enzymes for the corresponding analytes. By employing a floating-gate electrode structure, the electrical properties of the OFET vary upon the addition of an analyte on the extended gate. ${ }^{(26,27)}$ The changes in the electrical characteristics of the OFET stemming from the molecular recognition phenomena can be quantified using Eq. (1): ${ }^{(33)}$

$$
I_{D S}=\left(\frac{W}{2 L}\right) \mu C\left(V_{G S}-V_{T H}\right)^{2}
$$

where $I_{\mathrm{DS}}$ is the measured drain current, $W$ and $L$ are respectively the width and length of the 


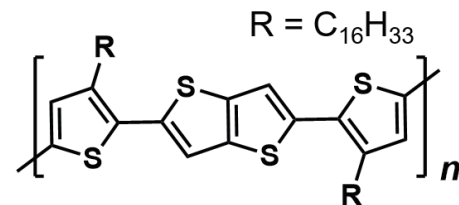

PBTTT

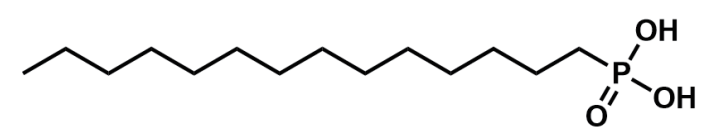

TDPA

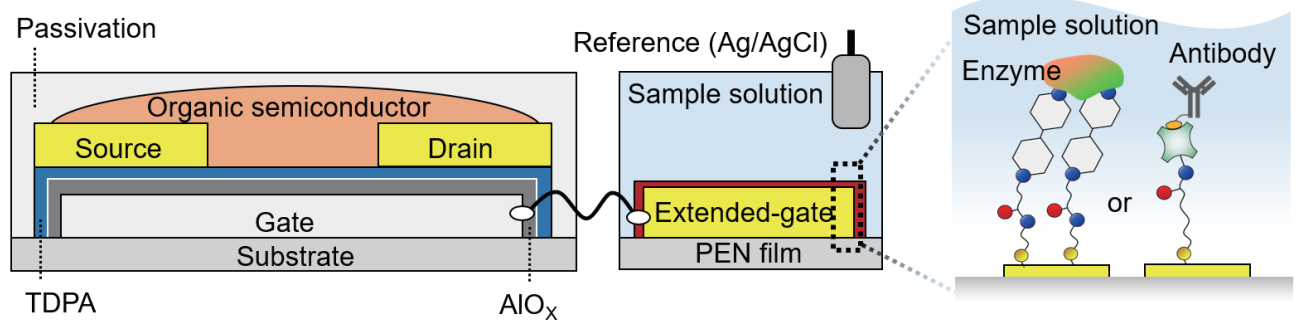

Fig. 1. (Color online) Schematic illustration of the extended-gate-type OFET.

channel, $\mu$ is the field-effect mobility, $C$ is the capacitance of the dielectric layer, $V_{\mathrm{GS}}$ is the voltage applied through the gate electrode, and $V_{\mathrm{TH}}$ is the threshold voltage.

With the accumulation of positively or negatively charged analytes on the electrode, electrical charge $(Q)$ and $V_{\mathrm{TH}}$ correlate according to the following equation:

$$
\Delta V_{T H}=\frac{\Delta Q}{C}
$$

Using this principle, we have successfully detected small ionic species and biomacromolecules. More information on OFET-based chemical sensor devices has been given in recent review articles. ${ }^{(24-27)}$

To operate at low voltages $(<|3 \mathrm{~V}|)$ and prevent the electrical degradation of the developed OFET, the design and optimization of the drive part are necessary. One way to achieve this is to improve the capacitance of the dielectric layer. ${ }^{(34)}$ To enhance the capacitance, we first deposited an aluminum gate electrode, which was oxidized by an oxygen plasma treatment involving reactive ion etching (RIE). Then, we employed a self-assembled monolayer (SAM) composed of tetradecylphosphonic acid (TDPA) ${ }^{(35)}$ as a dielectric bilayer for the gate electrode to increase the carrier concentration in the channel. Source and drain electrodes were then deposited by thermal vacuum deposition on the dielectric layer. One of the critical factors determining the properties of OFETs is the selection of the material for the organic semiconductor layer. Poly\{2,5-bis(3-hexadecylthiophene-2-yl)thieno[3,2-b]\}thiophene (PBTTT) is frequently used as the semiconductor material owing to its atmospheric stability and uniform electrical properties. ${ }^{(36)}$ PBTTT was drop-casted and baked, followed by the passivation of the semiconductor layer using Cytop ${ }^{\mathrm{TM}}$ (CTL-809M in CT-Solv 180). The extended gate, which is the detection part of the developed device, was obtained after Au deposition by thermal vacuum deposition on a polyethylene naphthalate (PEN) film. The extended gate can be subsequently functionalized by recognition materials to detect analytes. 
To evaluate the properties of the OFET, we obtained the initial transfer and output curves by measurement. The source electrode was connected to the ground, and then a sweep voltage was applied to the drain electrode. The gate voltage was applied through an $\mathrm{Ag} / \mathrm{AgCl}$ reference electrode. ${ }^{(37)}$ The OFET presented reproducible properties without any hysteresis after repeated measurements, demonstrating that it can be used as a biosensor.

\section{Low-voltage-operable Extended-gate-type OFET Used as a Psychological Stress Marker Sensor}

\subsection{Detection of CgA}

Chromogranin A (CgA; molecular weight $=48 \mathrm{kDa}$; made of 439 amino acid residues $)^{(38,39)}$ is an important soluble ${ }^{(38,40)}$ acidic glycoprotein, ${ }^{(41)}$ existing in the secretory granules of many endocrine and neuroendocrine cells. When an individual is exposed to a stressor, psychological stress can be observed by an increase in the CgA level. The benefits of $\mathrm{CgA}$ are its independence of the salivary flow rate and temperature, the short time lag between the stimulation and the maximum $\mathrm{CgA}$ level, ${ }^{(10)}$ and its durability. ${ }^{(42)}$ Importantly, salivary $\mathrm{CgA}$ is not bound to other proteins, in contrast to blood samples, ${ }^{(38)}$ and remains for a long time (up to $60 \mathrm{~min}$ ) in saliva after stimulation. ${ }^{(43)}$ Thus, $\mathrm{CgA}$ is a sensitive biomarker for psychophysical stress, ${ }^{(4)}$ such as exposure to situations inducing anxiety and depressive moods. ${ }^{(45)}$ In addition, serum $\mathrm{CgA}$ is an early biomarker for the monitoring of endocrine tumors, ${ }^{(46)}$ hypertensive heart failure, ${ }^{(38)}$ and neurodegenerative/neuropsychiatric diseases (e.g., amyotrophic lateral sclerosis (ALS) ${ }^{(10)}$ Alzheimer's disease, ${ }^{(38)}$ and Parkinson's disease. ${ }^{(47)}$ In other words, CgA is important for diagnosing chronic psychological stress and malfunction of the sympathetic nervous system. Although CgA can be detected by conventional biochemical methods such as immunoassay, ${ }^{(48)}$ they require relatively complicated treatments of samples (i.e., labeling prior to detection) and large equipment. Therefore, we developed an OFET-based biosensor, the extended gate of which was functionalized by an anti-CgA antibody [Fig. 2(a)]. ${ }^{(28)}$ The anti-CgA antibody was immobilized on the surface of the extended gate by avidin-biotin binding. The OFET exhibited changes in the transfer characteristics depending on the concentration of $\mathrm{CgA}$ in phosphatebuffered saline (PBS) containing $0.1 \mathrm{wt} \%$ human serum albumin (HSA). The observed changes stemmed from the changes in the nature of the charged surface of the extended gate, which leads to a positive shift of the transfer characteristics when the analyte is bound to the antibody on the extended-gate-type electrode. The limit of detection (LoD) and the limit of quantification (LoQ) are $0.31 \mu \mathrm{g} \cdot \mathrm{mL}^{-1}(\sim 6 \mathrm{nM})$ and $1.0 \mu \mathrm{g} \cdot \mathrm{mL}^{-1}(\sim 19 \mathrm{nM})$, respectively. These tests were also performed in artificial saliva (Saliveht ${ }^{\circledR}$, Teijin Pharma), in which the OFET device showed LoD and LoQ values of $0.11 \mu \mathrm{g} \cdot \mathrm{mL}^{-1}(\sim 2 \mathrm{mM})$ and $0.38 \mu \mathrm{g} \cdot \mathrm{mL}^{-1}(\sim 7 \mathrm{nM})$, respectively. Note that the developed OFET device needs an assay time of ca. $0.5 \mathrm{~h}$, which is approximately one-fifth of that of the conventional ELISA method (ca. 2.5 h). Furthermore, the sensor showed only small cross-reactive responses, as evident from a selectivity study with $\alpha$-amylase, IgA, and myeroperoxidase, implying the potential applicability of the OFET device for rapid $\mathrm{CgA}$ detection in a mixture [Fig. 2(c)]. 


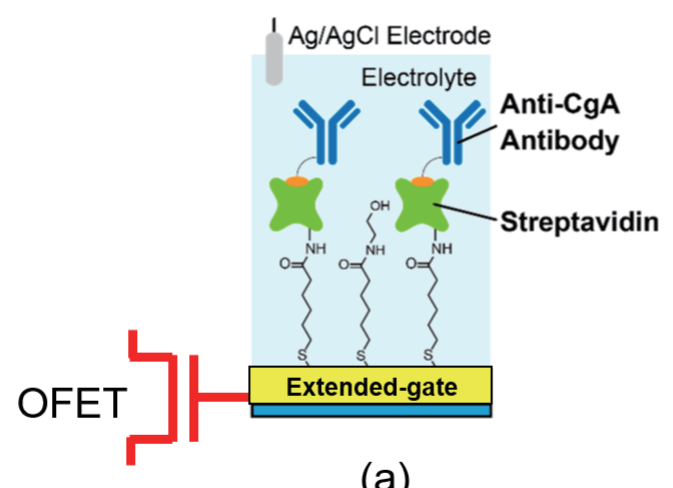

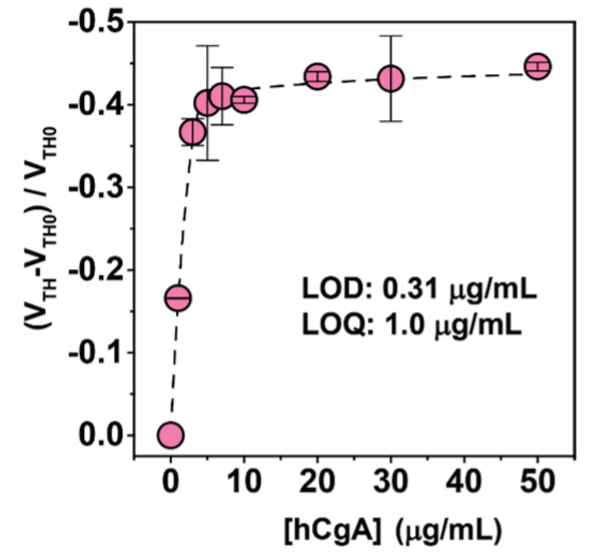

(b)

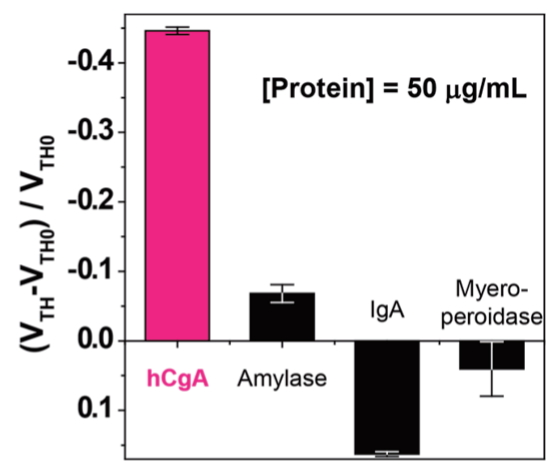

(c)

Fig. 2. (Color online) (a) Schematic illustration of the OFET functionalized by anti-CgA antibody. (b) Transfer characteristics $\left(I_{\mathrm{DS}}-V_{\mathrm{GS}}\right)$ of the OFET upon the addition of label-free human CgA in a PBS solution with $0.1 \mathrm{wt} \%$ HSA. $[\mathrm{CgA}]=0-50 \mu \mathrm{g} \cdot \mathrm{mL}^{-1}$. (c) Selectivity study for human $\mathrm{CgA}(\mathrm{hCgA})$ Reprinted with permission from Ref. 28. Licensed by Creative Commons Attribution 4.0 International (CC BY 4.0).

\subsection{Detection of salivary IgA}

IgA can be found in blood serum and in mucous secretion (i.e., saliva and tears). Several IgA can be found in blood serum and in mucous secretions (i.e., saliva and tears). Several studies have shown that the concentration of secretory $\operatorname{IgA}$ in saliva is altered in the case of infection and psychological stress, ${ }^{(10,49-51)}$ suggesting that the determination of the $\operatorname{IgA}$ level is crucial to manage such risks. To this end, we demonstrated the ability of an OFET-based sensor to detect $\operatorname{IgA}{ }^{(29)}$ We prepared a simulated saliva solution containing several interfering proteins $(\alpha$-amylase, lysozyme, lactoferrin, and myeloperoxidase). To comply with real biological conditions, the interferants were present at practical concentrations $\left([\alpha\right.$-amylase $]=0.4 \mu \mathrm{g} \cdot \mathrm{mL}^{-1}$, [lysozyme $]=$ $0.4 \mu \mathrm{g} \cdot \mathrm{mL}^{-1}$, [lactoferrin] $=1.0 \mu \mathrm{g} \cdot \mathrm{mL}^{-1}$, and [myeloperoxidase] $=3.6 \mu \mathrm{g} \cdot \mathrm{mL}^{-1}$ ). To detect IgA with an OFET-based device in saliva, a biotin-conjugated IgA antibody was immobilized on the extended-gate-type electrode as shown in Fig. 3(a). Because IgA is a dimeric biomolecule (molecular weight $=162 \mathrm{kDa}),{ }^{(52)}$ the distance between the Au electrode and the anti-IgA 


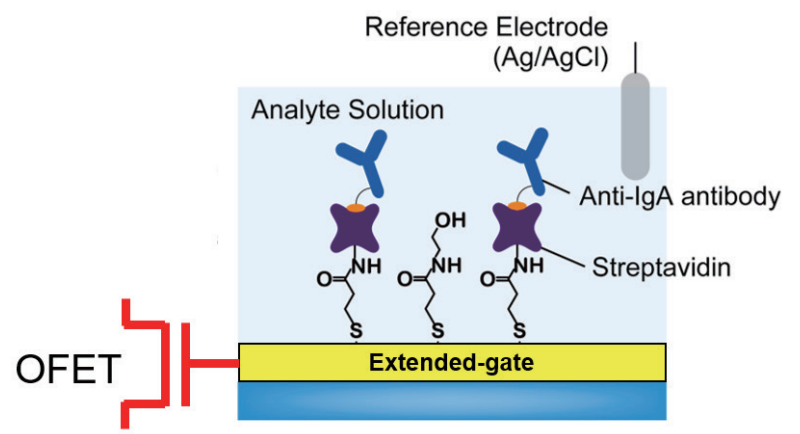

(a)

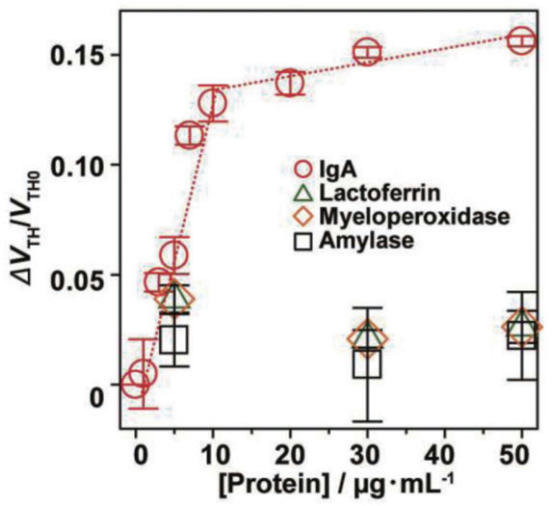

(b)

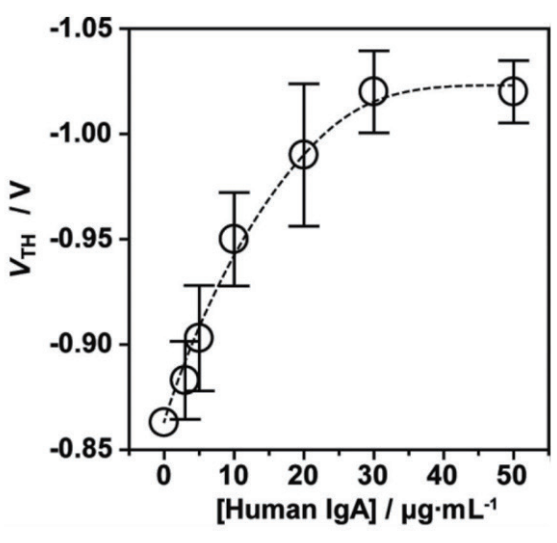

(c)

Fig. 3. (Color online) (a) Schematic illustration of the extended-gate-type OFET functionalized with antiIgA antibody. (b) Changes in the $V_{\mathrm{TH}}$ value of the OFET device upon the addition of IgA (circles), lactoferrin (triangles), myeloperoxidase (diamonds), or $\alpha$-amylase (squares) in a PBS solution with $0.1 \%$ wt HSA. [Proteins] $=0-50 \mu \mathrm{g} \cdot \mathrm{mL}^{-1}$. (c) Changes in the $V_{\mathrm{TH}}$ value of the OFET in the presence of various concentrations of IgA in a PBS solution containing $\alpha$-amylase $\left(0.4 \mu \mathrm{g} \cdot \mathrm{mL}^{-1}\right)$, lactoferrin $\left(1.0 \mu \mathrm{g} \cdot \mathrm{mL}^{-1}\right)$, lysozyme $\left(0.4 \mu \mathrm{g} \cdot \mathrm{mL}^{-1}\right)$, and myeloperoxidase $\left(3.6 \mu \mathrm{g} \cdot \mathrm{mL}^{-1}\right)$. $[\operatorname{IgA}]=0-50 \mu \mathrm{g} \cdot \mathrm{mL}^{-1}$. Reprinted with permission from Ref. 29. Copyright 2015 Japan Society for Analytical Chemistry.

antibody was shortened to similar to that for $\mathrm{CgA}$ to avoid adverse effects arising from Debye shielding [Figs. 2(a) and 3(a)]. ${ }^{(53)}$ Figure 3(b) shows the relationship between the concentration of the analytes and the $V_{\mathrm{TH}}$ value. The titration was performed in a PBS solution containing $0.1 \mathrm{wt} \% \mathrm{HSA}$, where the analyte concentration ranged between 0 and $50 \mu \mathrm{g} \cdot \mathrm{mL}^{-1}$. The OFET device provided a higher response to IgA than to the interfering species [Fig. 3(b)]. The LoD value was calculated as $2.1 \mu \mathrm{g} \cdot \mathrm{mL}^{-1}$, while saturation of the response was observed above a concentration of $10 \mu \mathrm{g} \cdot \mathrm{mL}^{-1}$. Furthermore, we realized the detection of human IgA in simulated saliva containing the above-mentioned interferants [Fig. 3(c)]. We also observed the change in $V_{\mathrm{TH}}$ with increasing IgA concentration. The titration isotherm showed a linear response of the OFET to IgA in the concentration range from 0 to $20 \mu \mathrm{g} \cdot \mathrm{mL}^{-1}$. Because the concentration of salivary IgA is higher than $40 \mu \mathrm{g} \cdot \mathrm{mL}^{-1}$ under healthy conditions, the developed OFET could be employed for monitoring the decrease in the IgA concentration under psychological stress. ${ }^{(54)}$ 


\subsection{OFET-based sensor for the detection of $\mathrm{NO}_{3}{ }^{-}$in human saliva}

Despite being used as a food additive and found in drinking water, $\mathrm{NO}_{3}{ }^{-}$can cause several diseases such as bladder cancer, ${ }^{(55)}$ stomach cancer, ${ }^{(56)}$ and infant methemoglobinemia ${ }^{(57)}$ in the case of overingestion. Moreover, numerous studies have shown that the $\mathrm{NO}_{3}{ }^{-}$concentration is closely related to the physical and psychological stresses of humans. ${ }^{(58,59)} \mathrm{NO}_{3}{ }^{-}$detection techniques based on colorimetric ${ }^{(60)}$ and fluorometric spectroscopy ${ }^{(61)}$ and inorganic field-effect transistors ${ }^{(62,63)}$ have been widely studied. On the other hand, $\mathrm{NO}_{3}{ }^{-}$detection by OFETs would enable the realization of low-cost and flexible organic sensor devices for daily monitoring of psychological stress. The mechanism of $\mathrm{NO}_{3}{ }^{-}$detection of the proposed OFET device is based on the reduction of $\mathrm{NO}_{3}{ }^{-}$by a nitrate reductase with a bipyridinium derivative $\left(\mathrm{BP}^{2+}\right)$ as an electron mediator [Fig. 4(a)]. The BP is converted to BP cation radicals through one-electron reduction by $\mathrm{Na}_{2} \mathrm{~S}_{2} \mathrm{O}_{4}$. The reduced form of $\mathrm{BP}$ is a source of electrons for the enzymatic

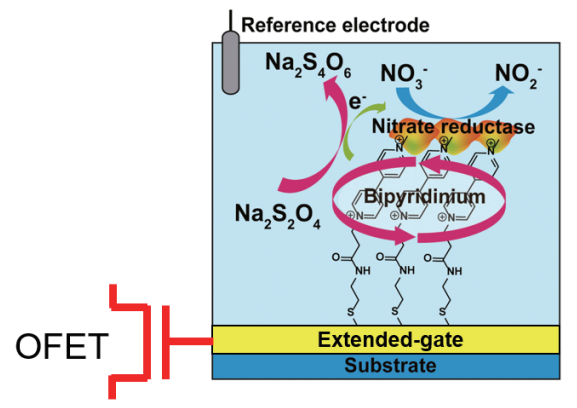

(a)

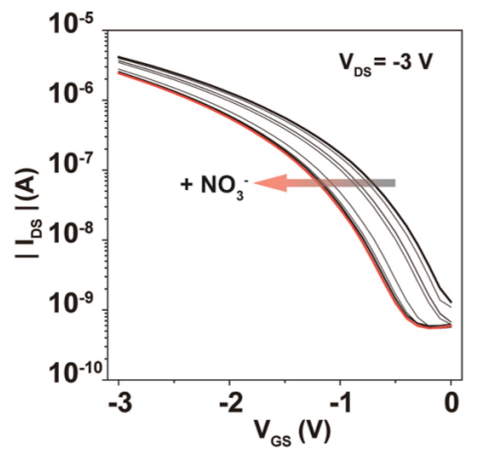

(b)

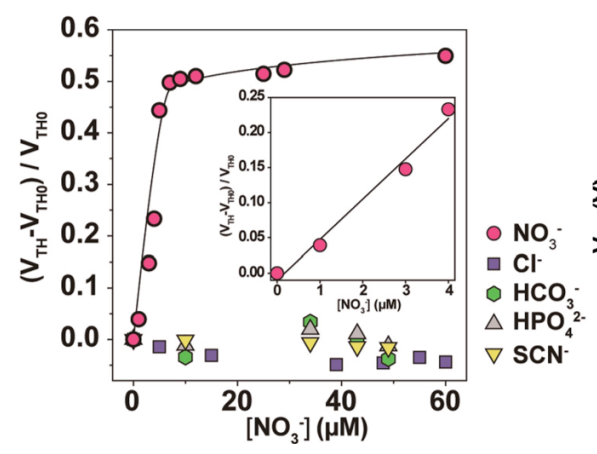

(c)

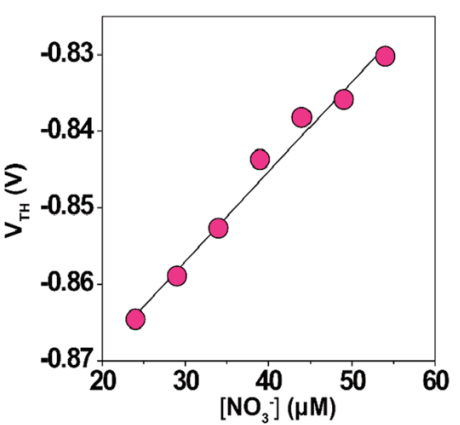

(d)

Fig. 4. (Color online) (a) Schematic illustration of the extended-gate-type OFET functionalized by nitrate reductase and a bipyridinium derivative for $\mathrm{NO}_{3}{ }^{-}$detection. (b) Transfer characteristics of the OFET upon titration with $\mathrm{NO}_{3}{ }^{-}$in a HEPES buffer solution $\left(10 \mathrm{mM}\right.$ ) at $\mathrm{pH} 7.4$ at room temperature. $\left[\mathrm{NO}_{3}{ }^{-}\right]=0-60 \mu \mathrm{M}$. (c) Changes in the $V_{\mathrm{TH}}$ value of the OFET upon the addition of $\mathrm{NO}_{3}{ }^{-}$(circles), $\mathrm{Cl}^{-}$(squares), $\mathrm{HCO}_{3}{ }^{-}$(hexagons), $\mathrm{HPO}_{4}{ }^{2-}$ (triangles), and $\mathrm{SCN}^{-}$(down-pointing triangles) at various concentrations in a HEPES buffer solution $(10 \mathrm{mM})$ at $\mathrm{pH} 7.4$ at room temperature. [anions] $=0-60 \mu \mathrm{M}$. (d) Changes in the $V_{\mathrm{TH}}$ value of the OFET in the presence of different concentrations of $\mathrm{NO}_{3}{ }^{-}$in diluted human saliva. $\left[\mathrm{NO}_{3}{ }^{-}\right]=24-54 \mu \mathrm{M} . R^{2}>0.98$. Reprinted with permission from Ref. 30. Copyright 2016 Elsevier Inc. 
reduction of $\mathrm{NO}_{3}^{-}$[Fig. 4(a)]. After obtaining evidence that the extended-gate-type electrode was functionalized by the enzyme, we first performed $\mathrm{NO}_{3}{ }^{-}$titration in a HEPES buffer solution in a concentration range of 0 to $60 \mu \mathrm{M}$. Consequently, the transfer characteristics of the OFET showed a negative shift with increasing $\mathrm{NO}_{3}{ }^{-}$concentration [Fig. 4(b)]. The $90 \%$ response time of the OFET to $\mathrm{NO}_{3}{ }^{-}$was within $20 \mathrm{~s}$, which is comparable to that of an inorganic FET-based $\mathrm{NO}_{3}{ }^{-}$sensor. ${ }^{(62)}$ The absence of $\mathrm{Na}_{2} \mathrm{~S}_{2} \mathrm{O}_{4}$ did not cause changes in the OFET characteristics, demonstrating the proof of concept. Subsequently, we investigated the selectivity of the device for $\mathrm{NO}_{3}{ }^{-}$using four other types of anionic species (i.e., $\mathrm{Cl}^{-}, \mathrm{HCO}_{3}^{-}, \mathrm{HPO}_{4}{ }^{2-}$, and $\mathrm{SCN}^{-}$). Figure 4(b) shows the change in $V_{\mathrm{TH}}$ as a function of the anion concentrations in the HEPES buffer solution. No responses were observed with the four other types of anionic species. From the titration isotherm in the linear range $(\sim 4 \mu \mathrm{M})$, the $\mathrm{LoD}$ value for $\mathrm{NO}_{3}{ }^{-}$was estimated as $45 \mathrm{ppb}$. Finally, we detected $\mathrm{NO}_{3}{ }^{-}$in diluted human saliva [Fig. 4(c)]. Although human saliva contains a variety of organic and inorganic ions and biomacromolecules, ${ }^{(64)}$ the $V_{\mathrm{TH}}$ value of the OFET device changed with the $\mathrm{NO}_{3}{ }^{-}$concentration. The recovery for the standard $\mathrm{NO}_{3}{ }^{-}$ solution added to the saliva samples was estimated to be $97.4 \pm 1.8 \%$, confirming that the developed OFET-based sensor could be employed to detect $\mathrm{NO}_{3}{ }^{-}$in a real sample.

\section{Conclusions}

In this Perspective, we summarized the development of extended-gate-type OFETs functionalized by antibodies or enzymes as biosensors for the detection of potential psychological stress biomarkers ( $\operatorname{IgA}, \mathrm{CgA}$, and $\left.\mathrm{NO}_{3}\right)$ ). The electrical properties of the OFET changed with the recognition of the analytes by the immune interaction or the enzymatic reaction for the analyte. Notably, the proposed biosensor allowed the detection of an analyte in mixtures, and may offer rapid analyses compared with the conventional immunoassays (i.e., ELISA). To accelerate the practical application of OFET-based sensor devices for psychological stress monitoring, we need to address the following points. (1) The chemical and thermal stabilities of the molecular recognition materials on the OFET need to be improved. In this regard, we have recently developed artificial molecular recognition materials for the detection of phosphoprotein, ${ }^{(27,65)}$ serum albumin, ${ }^{(27,66)}$ and lactate. ${ }^{(67)}$ Because these artificial materials have greater stability than natural materials, artificial materials for psychological stress markers also need to be developed toward future applications. (2) Detection accuracy should be considered from the viewpoint of stress diagnosis. Although OFET-based sensors show selectivity for target analytes due to the molecular recognition materials on the extended gate, pattern recognition ${ }^{(68)}$ combined with multiple measurements with the OFET sensor array would be effective to enhance the detection accuracy.

In our daily lives, simple, low-cost, and easy-to-use sensor devices to help manage daily stress are desirable. To this end, the proposed OFET devices functionalized by biomaterials are expected to pave the way for such sensor devices. Hence, we believe that our results will be useful for the future realization of OFET-based biosensors for healthcare applications. 


\section{Acknowledgments}

TM acknowledges financial support from JSPS KAKENHI (Grant Numbers JP20H05207 and JP20K21204). PD gratefully acknowledges Research Fellowships for Postdoctoral Fellows from JSPS (Grant Number JP18F18800). YS thanks the JSPS Research Fellowship for Young Scientists (DC1) (Grant Number JP18J21190). This work was partially supported by the JSPS Core-to-Core Program (A. Advanced Research Networks). We also thank AGC for supplying Cytop.

\section{References}

1 H. Yaribeygi, Y. Panahi, H. Sahraei, T. P. Johnston, and A. Sahebkar: EXCLI J. 16 (2017) 1057. https://doi. org/10.17179/excli2017-480.

2 M. Moreno-Smith, S. K. Lutgendorf, and A. K. Sood: Future Oncol. 6 (2010) 1863. https://doi.org/10.2217/ fon. 10.142

3 M. W. Linn, B. S. Linn, J. S. Skyler, and J. Jensen: Clin. Immunol. Immunopathol. 27 (1983) 223. https://doi. org/10.1016/0090-1229(83)90072-7

4 T. G. Guilliams and L. Edwards: The Standard 9 (2010) 1. https://www.pointinstitute.org/wp-content/ uploads/2012/10/standard_v_9.2 hpa_axis.pdf

5 V. T. Cunliffe: Epigenomics 8 (2016) 1653. https://doi.org/10.2217/epi-2016-0075

6 A. M. Stankiewicz, A. H. Swiergiel, and P. Lisowski: Brain Res. Bull. 98 (2013) 76. https://doi.org/10.1016/ j.brainresbull.2013.07.003

7 M. R. Salleh: Malays. J. Med. Sci. 15 (2008) 9. https://www.ncbi.nlm.nih.gov/pmc/articles /PMC3341916/

8 D. P. Lima, D. G. Diniz, S. A. S. Moimaz, D. H. Sumida, and A. C. Okamoto: Int. J. Infect. Dis. 14 (2010) e184. https://doi.org/10.1016/j.ijid.2009.04.022

9 M. Greabu, M. Battino, M. Mohora, A. Totan, A. Didilescu, T. Spinu, C. Totan, D. Miricescu, and R. Radulescu: J. Med. Life 2 (2009) 124. https://www.ncbi.nlm.nih.gov/pmc/articles/PMC3018981/

10 K. Obayashi: Clin. Chim. Acta 425 (2013) 196. https://doi.org/10.1016/j.cca.2013.07.028

11 S. Chiappin, G. Antonelli, R. Gatti, and E. F. De Palo: Clin. Chim. Acta 383 (2007) 30. https://doi.org/10.1016/ j.cca.2007.04.011

12 M. Gröschl: Clin. Chem. 54 (2008) 1759. https://doi.org/10.1373/clinchem.2008.108910

13 D. C. Slavish and Y. Z. Szabo: Syst. Rev. 8 (2019) 108. https://doi.org/10.1186/s13643-019-1026-4

14 B. J. van Holland, M. H. W. Frings-Dresen, and J. K. Sluiter: Int. Arch. Occup. Environ Health 85 (2012) 849. https://doi.org/10.1007/s00420-011-0727-3

15 J. A. Loo, W. Yan, P. Ramachandran, and D. T. Wong: J. Dent. Res. 89 (2010) 1016. https://doi. org $/ 10.1177 / 0022034510380414$

16 R. Vineetha, K.-M. Pai, M. Vengal, K. Gopalakrishna, and D. Narayanakurup: J. Clin. Exp. Dent. 6 (2014) e132. https://doi.org/10.4317/jced.51355

17 C. D. Conrad: Rev. Neurosci. 19 (2008) 395. https://doi.org/10.1515/revneuro.2008.19.6.395

18 H. Klauk: Chem. Soc. Rev. 39 (2010) 2643. https://doi.org/10.1039/B909902F

19 Y. Wen, Y. Liu, Y. Guo, G. Yu, and W. Hu: Chem. Rev. 111 (2011) 3358. https://doi.org/10.1021/cr1001904

20 M. Muccini: Nat. Mater. 5 (2006) 605. https://doi.org/10.1038/nmat1699

21 A. R. Murphy and J. M. Fréchet: Chem. Rev. 107 (2007) 1066. https://doi.org/10.1021/cr0501386

22 J. Mei, Y. Diao, A. L. Appleton, L. Fang, and Z. Bao: J. Am. Chem. Soc. 135 (2013) 6724. https://doi. org/10.1021/ja400881n

23 H. Sirringhaus: Adv. Mater. 26 (2014) 1319. https://doi.org/10.1002/adma.201304346

24 T. Minami, T. Minamiki, and Y. Sasaki: Electrochemistry 86 (2018) 303. https://doi.org/10.5796/ electrochemistry.18-6-E2672

25 T. Minamiki, Y. Sasaki, S. Su, and T. Minami: Polym. J. 51 (2019) 1. https://doi.org/10.1038/s41428-018-0112-0

26 R. Kubota, Y. Sasaki, T. Minamiki, and T. Minami: ACS Sens. 4 (2019) 2571. https://doi.org/10.1021/ acssensors.9b01114

27 T. Minamiki, R. Kubota, Y. Sasaki, K. Asano, and T. Minami: ChemistryOpen 9 (2020) 573. https://doi. org/10.1002/open.202000025 
28 T. Minamiki, T. Minami, Y. Sasaki, S. Wakida, R. Kurita, O. Niwa, and S. Tokito: Sensors 16 (2016) 2033. https://www.mdpi.com/1424-8220/16/12/2033

29 T. Minamiki, T. Minami, Y. Sasaki, R. Kurita, O. Niwa, S. Wakida, and S. Tokito: Anal. Sci. 31 (2015) 725. https://doi.org/10.2116/analsci.31.725

30 T. Minami, Y. Sasaki, T. Minamiki, S. Wakida, R. Kurita, O. Niwa, and S. Tokito: Biosens. Bioelectron. 81 (2016) 87. https://doi.org/10.1016/j.bios.2016.02.036

31 T. Minamiki, T. Minami, R. Kurita, O. Niwa, S. Wakida, K. Fukuda, D. Kumaki, and S. Tokito: Appl. Phys. Lett. 104 (2014) 243703. https://doi.org/10.1063/1.4883739

32 T. Minamiki, T. Sekine, M. Aiko, S. Su, and T. Minami: Sens. Mater. 31 (2019) 99. https://doi.org/10.18494/ SAM.2019.2082

33 G. Horowitz: Adv. Mater. 10 (1998) 365. https://onlinelibrary.wiley.com/ https://doi.org/10.1002/(SICI)15214095(199803)10:5\%3C365::AID-ADMA365\%3E3.0.CO;2-U

34 H. Klauk, U. Zschieschang, J. Pflaum, and M. Halik: Nature 445 (2007) 745. https://doi.org/10.1038/ nature 05533

35 K. Fukuda, T. Hamamoto, T. Yokota, T. Sekitani, U. Zschieschang, H. Klauk, and T. Someya: Appl. Phys. Lett. 95 (2009) 203301. https://doi.org/10.1063/1.3259816

36 I. McCulloch, M. Heeney, C. Bailey, K. Genevicius, I. Macdonald, M. Shkunov, D. Sparrowe, S. Tierney, R. Wagner, W. Zhang, M. L. Chabinyc, R. J. Kline, M. D. McGehee, and M. F. Toney: Nat. Mater. 5 (2006) 328. https://doi.org/10.1038/nmat1612

37 P. Bergveld: Sens. Actuators, B 88 (2003) 1. https://doi.org/10.1016/S0925-4005(02)00301-5

38 M. A. D’Amico, B. Ghinassi, P. Izzicupo, L. Manzoli, and A. Di Baldassarre: Endocr. Connect. 3 (2014) R45. https://doi.org/10.1530/ec-14-0027

39 M. Stridsberg, B. Eriksson, K. Oberg, and E. T. Janson: J. Endocrinol. 177 (2003) https://doi.org/10.1677/ joe. 0.1770337

40 R. J. Parmer, X. P. Xi, H. J. Wu, L. J. Helman, and L. N. Petz: J. Clin. Invest. 92 (1993) 1042. https://doi. org/10.1172/JCI116609

41 B. H. Fasciotto, J. C. Denny, G. H. Greeley Jr., and D. V. Cohn: Peptides 21 (2000) 1389. https://doi. org/10.1016/S0196-9781(00)00283-7

42 F. Sato, T. Kanno, S. Nagasawa, N. Yanaihara, N. Ishida, T. Hasegawa, and T. Iwanaga: Cells Tissues Organs 172 (2002) 29. https://doi.org/10.1159/000064389

43 D. T. O'Connor: Hypertension 7 (1985) I-76. https://www.ahajournals.org/ https://doi.org/10.1161/01.HYP.7.3 Pt_2.I76

44 Y. Kanamaru, A. Kikukawa, and K. Shimamura: Stress 9 (2006) 127. https://doi. org/10.1080/14769670600909594

45 Y. Li, Y. Song, W. Dang, L. Guo, and W. Xu: J. Occup. Health 62 (2020) e12113. https://doi.org/10.1002/13489585.12113

46 J. M. Conlon: Regul. Pept. 165 (2010) 5. https://doi.org/10.1016/j.regpep.2009.11.013

47 M. Kaiserova, H. P. Vranova, J. Galuszka, D. Stejskal, K. Mensikova, J. Zapletalova, J. Mares, and P. Kanovsky: Neurology 84 (2015) P1.266. https://n.neurology.org/content/84/14_Supplement/P1.266

48 D. S. Hage: Anal. Chem. 71 (1999) 294. https://doi.org/10.1021/a1999901

49 S. Tsujita and K. Morimoto: Environ. Health Prev. Med. 4 (1999) 1. https://doi.org/10.1007/BF02931243

50 E. A. Shirtcliff, D. A. Granger, E. Schwartz, and M. J. Curran: Psychoneuroendocrinology 26 (2001) 165. https://doi.org/10.1016/S0306-4530(00)00042-1

51 Y. Yang, D. Koh, V. Ng, C. Y. Lee, G. Chan, F. Dong, S. H. Goh, V. Anantharaman, and S. E. Chia: Occup. Environ. Med. 59 (2002) 836. https://doi.org/10.1136/oem.59.12.836

52 D. J. Dietzen: Principles and Applications of Molecular Diagnostics, N. Rifai, A. R. Horvath, C. T. Wittwer, Eds. (Elsevier, 2018) p. 345.

53 T. Goda and Y. Miyahara: Langmuir 28 (2012) 14730. https://doi.org/10.1021/la302977s

54 C. G. Engeland, F. N. Hugo, J. B. Hilgert, G. G. Nascimento, R. Junges, H. J. Lim, P. T. Marucha, and J. A. Bosch: Brain. Behav. Immun. 52 (2016) 11. https://doi.org/10.1016/j.bbi.2015.08.017

55 H. F. Chiu, S. S. Tsai, and C. Y. Yang: J. Toxicol. Environ. Health A 70 (2007) 1000. https://doi. org/10.1080/15287390601171801

56 N. S. Bryan, D. D. Alexander, J. R. Coughlin, A. L. Milkowski, and P. Boffetta: Food Chem. Toxicol. 50 (2012) 3646. https://doi.org/10.1016/j.fct.2012.07.062

57 D. L. Shrock and M. D. Krasowski: Toxicology Cases for the Clinical and Forensic Laboratory, H. Ketha and U. Garg Eds. (Academic Press, 2020) p. 469.

58 L. Jin, L. Qin, D. Xia, X. Liu, Z. Fan, C. Zhang, L. Gu, J. He, I. S. Ambudkar, D. Deng, and S. Wang: Free Radical Biol. Med. 57 (2013) 61. https://doi.org/10.1016/j.freeradbiomed.2012.12.015 
59 O. S. Gammoh, A. M. Al-Smadi, A. F. Ashour, and W. Al-Awaida: Psychiatry Investig. 13 (2016) 311. https:// doi.org/10.4306/pi.2016.13.3.311

60 M. I. C. Monteiro, F. N. Ferreira, N. M. M. de Oliveira, and A. K. Ávila: Anal. Chim. Acta 477 (2003) 125. https://doi.org/10.1016/S0003-2670(02)01395-8

61 S. Biswas, B. Chowdhury, and B. C. Ray: Talanta 64 (2004) 308. https://doi.org/10.1016/j.talanta.2004.02.018

62 M. Zayats, A. B. Kharitonov, E. Katz, and I. Willner: Analyst 126 (2001) 652. https://doi.org/10.1039/ B102363M

63 S. Wakida, T. Okamura, Y. Shibutani, and J. Liu: Sens. Mater. 19 (2007) 235. https://myukk.org/SM2017/ article.php?ss=486

64 S. P. Humphrey and R. T. Williamson: J. Prosthet. Dent. 85 (2001) 162. https://doi.org/10.1067/ mpr.2001.113778.

65 T. Minamiki, T. Minami, P. Koutnik, P. Anzenbacher, Jr., and S. Tokito: Anal. Chem. 88 (2016) 1092. https:// doi.org/10.1021/acs.analchem.5b04618

66 T. Minamiki, Y. Sasaki, S. Tokito, and T. Minami: ChemistryOpen 6 (2017) 472. https://doi.org/10.1002/ open. 201700070

67 P. Didier and T. Minami: Semicond. Sci. Technol. (in press). https://iopscience.iop.org/ article/10.1088/1361-6641/abb288

68 Y. Sasaki, S. Kojima, V. Hamedpour, R. Kubota, S. Takizawa, I. Yoshikawa, H. Houjou, Y. Kubo, and T. Minami: Chem. Sci. 11 (2020) 3790. https://doi.org/10.1039/D0SC00194E

\section{About the Authors}

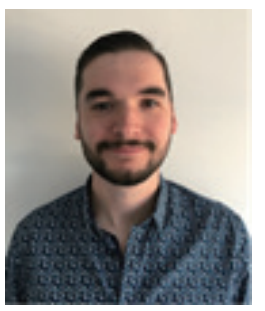

Pierre Didier was born in Thionville, France. He received his B.Eng. degree (2011) from the University of Lorraine and his M.Eng. degree (2013) from Paris XIII University. Then he obtained his Ph.D. degree from ENS Paris Saclay under the direction of Professor Pascal Larzabal in 2017. From 2016 to 2018, he was an assistant lecturer at ENS Rennes, France. In 2018, he joined the University of Tokyo at the LIMMS and the Minami Lab as a JSPS postdoctoral fellow. His research interests are in biosensors, instrumentation, and medical diagnosis systems. (p-didier@iiis.u-tokyo.ac.jp)

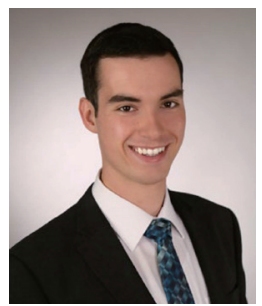

Hans Blomenkamp was born in Selb, Germany in 1997. He is currently a nanotechnology student specializing in semiconductor technology at the Technical University Bergakademie of Freiberg, Germany. He worked at the Institute for Electronic and Sensor Materials with Professor Yvonne Joseph on a MEMS biosensor for the detection of antibiotics in wastewater, and he was an intern at the Minami Lab at the Institute of Industrial Science at the University of Tokyo. (hans.blomenkamp@gmail.com)

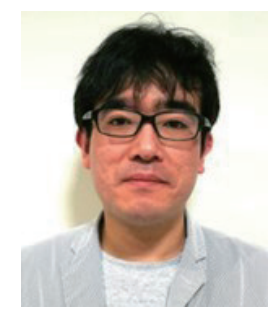

Riku Kubota was born in 1988 in Saitama, Japan. He received his Ph.D. degree in engineering from Tokyo Metropolitan University in 2016 under the supervision of Professor Hiroyoshi Kawakami. Between 2016 and 2019, he worked with the same group, where he was engaged in the development of metallo-porphyrins for biomedical applications and supramolecular systems for redox catalyses. Currently, he is a project research associate at the University of Tokyo, working with Associate Professor Tsuyoshi Minami. His current research focuses on supramolecular materials for organic field-effect transistors and optical chemosensor arrays. (r-kubota@iis.u-tokyo.ac.jp) 


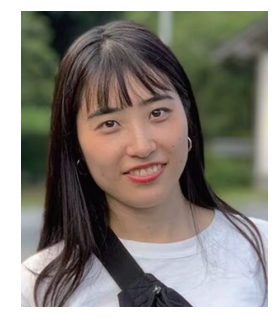

Yui Sasaki was born in Aomori, Japan in 1992. She received her Ph.D. degree from the University of Tokyo in 2020 under the supervision of Associate Professor Tsuyoshi Minami. She was a JSPS Research Fellow for Young Scientists (DC1) at the University of Tokyo. Currently, she is a JSPS postdoctoral fellow (PD) at the same university. During her Ph.D. course, she worked with Professor Yang Tian of East China Normal University (China) in 2019 and Professor Karsten Haupt of University of Technology of Compiègne (France) in 2020 on collaborative projects. Her research interests include molecular self-assembled systems for chemical sensors.

(sayui@iis.u-tokyo.ac.jp)

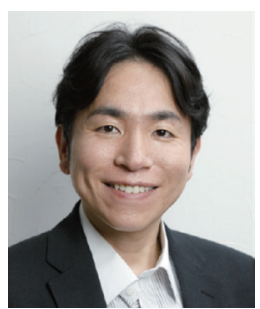

Tsuyoshi Minami was born in Saitama, Japan in 1983. He received his B.Eng. (2006) and M.Eng. (2008) degrees from Saitama University; he then obtained his Ph.D. degree from Tokyo Metropolitan University under the direction of Professor Yuji Kubo in 2011. During his Ph.D. studies, he worked with Professor Tony D. James of University of Bath on collaborative projects. Between 2011 and 2013, he was a postdoctoral research associate at Bowling Green State University, working with Professor Pavel Anzenbacher, Jr. In 2013, he was appointed as a research assistant professor at the same university. Then, he moved to Yamagata University in 2014, where he worked as an assistant professor. He was appointed as a lecturer at the University of Tokyo in 2016, and he became an associate professor at the same university in 2019. He is also a visiting associate professor at Yamagata University and Tokyo Metropolitan University. His interests include supramolecular analytical chemistry, self-assembled materials, gold nanoparticles, and organic transistors for sensing applications. (tminami@iis.u-tokyo.ac.jp) 